\title{
Synthesis of 1-D ZnO nanorods and polypyrrole/1-D ZnO nanocomposites for photocatalysis and gas sensor applications
}

\author{
PRITAM PATIL ${ }^{1}$, GANESH GAIKWAD ${ }^{1}$, D R PATIL ${ }^{2}$ and JITENDRA NAIK ${ }^{1, *}$ \\ ${ }^{1}$ Department of Chemical Engineering, University Institute of Chemical Technology, North Maharashtra University, \\ Jalgaon 425001, India \\ ${ }^{2}$ Bulk and Nanomaterials Research Laboratory, Rani Laxmibai Mahavidyalaya Parola, Jalgaon 425111, India
}

MS received 5 June 2015; accepted 28 December 2015

\begin{abstract}
D ZnO nanorods and PPy/1-D ZnO nanocomposites were prepared by the surfactant-assisted precipitation and in situ polymerization method, respectively. The synthesized nanorods and nanocomposites were characterized by UV-Vis spectrophotometer, Fourier transform-infrared spectroscopy (FTIR), X-ray diffraction (XRD) and field emission scanning electron microscope (FE-SEM), which gave the evidence of 1-D ZnO nanorods, polymerization of pyrrole monomer and strong interaction between PPy and 1-D ZnO nanorods, respectively. Photocatalytic activity of 1-D $\mathrm{ZnO}$ nanorods was conducted by $3^{3}$ level full-factorial design to evaluate the effect of three independent process variables viz., dye concentration (crystal violet), catalyst concentration (1-D $\mathrm{ZnO}$ nanorods) and the reaction time on the preferred response: photodegradation efficiency (\%). The PPy/1-D ZnO nanocomposites were used for the sensing of $\mathrm{NH}_{3}, \mathrm{LPG}, \mathrm{CO}_{2}$ and $\mathrm{H}_{2} \mathrm{~S}$ gases, respectively, at room temperature. It was observed that PPy/1-D ZnO nanocomposites with different 1-D $\mathrm{ZnO}$ nanorod weight ratios (15 and $25 \%$ ) had better selectivity and sensitivity towards $\mathrm{NH}_{3}$ at room temperature.
\end{abstract}

Keywords. 1-D ZnO nanorods; PPy/1-D ZnO nanocomposites; photocatalytic activity; sensitivity.

\section{Introduction}

The synthesis of zinc oxide $(\mathrm{ZnO})$ nanostructures such as nanoparticles, nanowires, nanorods, etc., has gained increasing research importance due to their unique properties and potential applications in various fields, such as gas sensing, solar cell, microelectronics, pharmaceutics, photovoltaic and catalysis [1-9]. In the past two decades, $\mathrm{ZnO}$ nanostructures have prominent attribute because of its stability, wide band gap energy of $3.37 \mathrm{eV}$ and large excitation binding energy of $60 \mathrm{meV}$ at room temperature [10-13]. In addition, $\mathrm{ZnO}$ nanostructures offer a larger surface area to volume ratio than nanoparticulate thin films, owing to this characteristic advantage, it plays an important role in photodegradation [14]. However, this property has made $\mathrm{ZnO}$ as one of the most appealing photocatalyst semiconductor material for the degradation of organic pollutants in water under UV source. As a family of catalyst materials, $\mathrm{ZnO}$ nanostructures have been successfully prepared by variety of synthetic techniques. Among these techniques, the well-known precipitation method [15] is more useful and cost effective method. Kumar et al [16] prepared $\mathrm{ZnO}$ nanorods by a precipitation method with zinc sulphate and sodium hydroxide as starting materials followed by calcination. In this study, we use precipitation method for the synthesis of 1-D ZnO nanorod. The shape and size controlled 1-D ZnO nanorod synthesis is quite

\footnotetext{
*Author for correspondence (jitunaik@gmail.com)
}

difficult via a precipitation method, because the growth rate is too fast for the precursor to control the size. To overcome this difficulty, CTAB used as a structure directing surfactant [17].

The output of textile or dyestuff industries consists of coloured wastewater and dyes have more impact on the environment [18]. Among the wide range of dyes, crystal violet is a triphenylmethane dye which is highly toxic and carcinogenic $[18,19]$. Many techniques involving reverse osmosis, flocculation, chemical oxidation and reduction, electrochemical treatment and photocatalysis have been investigated for the treatment of crystal violet (CV) wastewater [20]. Of these, semiconductor-assisted photocatalysis has a prominent attribute because it is very effective to treat pollutants in both gas and liquid phases [21].

In this era with increased presence of pollutant gases in the atmosphere, it has become very essential to detect hazardous gases in standpoint of human safety measures. $\mathrm{ZnO}$ is a strong candidate for monitoring lethal gases because of its high electrochemical stability, good resistivity and excellent sensitivity towards gas pollutants [22]. Still, high operating temperature $\left(350-450^{\circ} \mathrm{C}\right)$ of $\mathrm{ZnO}$ limits its real-time application. Conducting polymers (CPs) also show attractive gas sensing properties. Polypyrrole (PPy) is environmentally stable, can be easily prepared by chemical or electrochemical oxidative polymerization and have higher conductivity than other CPs [23]. However, metal oxide conducting polymer composites have been found to indicate smart sensing properties. PPy is a p-type material, while $\mathrm{ZnO}$ is n-type of material by tailoring this inorganic-organic composite, it is possible 
to make tunable conductivity sensors for better selectivity [24]. Some well-known materials for $\mathrm{NH}_{3}$ gas sensing are $\mathrm{ZnO}$, modified-ZnO [25], polyaniline [26], polypyrrole [27], $\mathrm{Au}$ and $\mathrm{MoO}_{3}$-modified $\mathrm{WO}_{3}[28,29]$, $\mathrm{Pt}$ and $\mathrm{SiO}_{2}$-doped $\mathrm{SnO}_{2}$ [30], etc. Various ammonia sensors reported, basically work at higher temperature such as $350^{\circ} \mathrm{C}$, but it is inconvenient to attain such high temperature while sensing. So, the sensors operable at room temperature are needed. The electrolytic techniques using diaphragm electrodes are generally used for the detection of ammonia. However, this method is expensive and does not have sufficient response and selectivity for ammonia [31]. Another technique utilizes Pd-metal oxide semiconductor MOS device. This device is sensitive to ammonia, but it suffers from selectivity. So, semiconducting oxide sensors are considered here. Few sensor models are also available for detecting ammonia gas. They are: Figaro gas sensor model-TGS 824 (detection range $300 \mathrm{ppm}$ ) and Sierra gas monitor model-CM 99-447 (electrochemical type, detection range $200 \mathrm{ppm}$ ).

Despite of high sensitivity, selectivity and long-term stability, the main drawback of such sensors is that they operate at high working temperature $\left(>300^{\circ} \mathrm{C}\right)$. Also, the use of metal additives likes Pt, Pd, Au, Ag, etc. in base material like $\mathrm{ZnO}$ for the modification, increases the cost of the sensors. Therefore, the applicability of these sensors remains limited. Hence, the sensors operable at room temperature with the low-cost metal additives must be developed for large applicability. In the present work, we have used 1-D $\mathrm{ZnO}$ nanorod for photocatalytic degradation of crystal violet and its nanocomposite with polypyrrole to develop the room temperature ammonia sensors.

\section{Materials and methods}

\subsection{Materials}

Zinc sulphate heptahydrate $\left(\mathrm{ZnSO}_{4} \cdot 7 \mathrm{H}_{2} \mathrm{O}\right.$, Merck), Iron chloride $\left(\mathrm{FeCl}_{3}\right.$, Merck) and sodium hydroxide $(\mathrm{NaOH}$, S.D. Fine Chem. Ltd) were used as received. Cetyltrimethylammonium bromide (CTAB, Spectrochem) was used as the stabilizing agent, pyrrole monomer (Sigma-Aldrich) was used for the synthesis of PPy/ZnO nanocomposite. All other chemicals were of analytical grade and used as received. Double-distilled water was used throughout the experiments.

\subsection{Synthesis of 1-D ZnO nanorods}

1-D $\mathrm{ZnO}$ nanorods were synthesized by the surfactantassisted precipitation method followed by calcination. In brief, $\mathrm{ZnSO}_{4} \cdot 7 \mathrm{H}_{2} \mathrm{O}$ and $\mathrm{NaOH}$ were taken as the precursors of the synthesis process. Both precursors were dissolved separately in double-distilled water to obtain molar ratio ( $1: 1$ to $1: 4)$ of solutions. $\mathrm{ZnSO}_{4} \cdot 7 \mathrm{H}_{2} \mathrm{O}$ solution $(50 \mathrm{ml})$ was added drop by drop and vigorously stirred in $\mathrm{NaOH}$ and CTAB solution. The addition rate of $\mathrm{ZnSO}_{4} \cdot 7 \mathrm{H}_{2} \mathrm{O}$ solution was maintained using a syringe pump (Infusor, Universal Medical
Instruments, India). The white precipitate product obtained, filtered, washed and dried at $70^{\circ} \mathrm{C}$ in an oven for $2 \mathrm{~h}$. Finally, the resultant product was calcined at $200^{\circ} \mathrm{C}$ for $4 \mathrm{~h}[32,33]$.

\subsection{Synthesis of PPy/1-D ZnO nanocomposite}

PPy/1-D ZnO nanocomposite was synthesized by in situ polymerization [34] of pyrrole monomer in the presence of 1-D $\mathrm{ZnO}$ nanorods. 1-D $\mathrm{ZnO}$ was dispersed in $50 \mathrm{ml}$ of $0.35 \mathrm{M} \mathrm{FeCl}_{3}$ solution for 10 min using bath sonicator. Then, $1 \mathrm{ml}$ of pyrrole monomer added drop by drop into the solution under stirring. Vigorous stirring of the mixture for $3 \mathrm{~h}$ resulted in a black coloured solution, which was filtered and washed repeatedly with double-distilled water. The solid product obtained was dried in an air oven for $4 \mathrm{~h}$.

\subsection{Characterization}

Degradation performance of $\mathrm{CV}$ dye was examined by UV-Vis spectrophotometer (HITACHI U-2900, Tokyo, Japan). The surface morphology of the products was examined by scanning electron microscopy (FESEM-S 4800, Hitachi, Japan) at a working distance of $8.6-8.8 \mathrm{~mm}$ and accelerating voltage of $15.0 \mathrm{kV}$. The components of materials were measured by a FTIR spectrophotometer (FTIR-8400; Shimadzu, Asia Pacific Pvt. Ltd, Singapore) by potassium bromide pellet method. For that, sample (1 mg) was mixed with $\mathrm{KBr}(40 \mathrm{mg})$ and compressed into a disc in a manual press. Spectra were recorded in the wavelength region of 4000 $400 \mathrm{~cm}^{-1}$. The physical nature of the samples was examined by an X-ray diffractometer (Bruker, D8 Advanced, Germany) with $\mathrm{CuK} \alpha$ radiation $(\lambda=1.5406 \AA$ Á). The anode $\mathrm{X}$-ray tube was operated at $40 \mathrm{kV}$ and $40 \mathrm{~mA}$. The samples were analysed over the angle range $0-80^{\circ}$ on the $2 \theta$ scale at a step size of $0.03 \mathrm{~s}^{-1}$.

\subsection{Photodegradation experiments}

The photodegradation of $\mathrm{CV}$ dye was performed under UV light source. The aqueous suspension of $\mathrm{CV}$ was prepared by adding a known quantity of $\mathrm{ZnO}$ nanorod powder into a solution containing a suitable concentration of CV. Then, the suspension was magnetically stirred in the dark for $1 \mathrm{~h}$ to allow an adsorption-desorption equilibrium between $\mathrm{CV}$ and the surface of the 1-D $\mathrm{ZnO}$ nanorod catalyst. Irradiation was carried out in a quartz cell located at $10 \mathrm{~cm}$ away from the source. At known time interval, the decomposed dye sample was withdrawn, centrifuged and then filtered. The quantitative analysis of CV was carried out using UV-Vis spectrophotometer (Hitachi U 2900, Tokyo, Japan) by measuring absorbance at $590 \mathrm{~nm}$ [35]. The photodegradation efficiency of $\mathrm{CV}$ dye was calculated according to the following equation,

$$
\text { Efficiency }=C_{0}-C / C_{0} * 100=A_{0}-A_{\mathrm{t}} / A_{0} * 100 .
$$


Table 1. Variables and three levels.

\begin{tabular}{lccc}
\hline & Low level $(-1)$ & Medium level (0) & High level $(+1)$ \\
\hline Independent variable & & 7.5 & 10 \\
$A=$ Conc. of dye (ppm) & 5 & 0.5 & 1.0 \\
$B=$ Conc. of catalyst $\left(\mathrm{g}^{-1}\right)$ & 0.1 & 60 & 120 \\
$C=$ Reaction time (min) & 0 & & \\
Dependent variable & & & \\
Y1 $=$ Photodegradation & & & \\
Efficiency or \% degradation & & & \\
\hline
\end{tabular}

Various factors were evaluated in the degradation of CV dye using $3^{3}$ level full-factorial design. The selection of 3 level factorial design is suitable for investigating the quadratic response surface model based on the second-order polynomial equation $[36,37]$. The independent variables selected were the concentration of dye $(A, \mathrm{ppm})$, concentration of catalyst $\left(B, \mathrm{~g}^{-1}\right)$ and reaction time $(C, \mathrm{~min})$, which were varied at three levels $(-1,0,+1)$. Table 1 shows $3^{3}$ experimental design with 3 independent variables $(A, B, C)$ at 3 different levels $(-1,0,+1)$ was used to study the effects on the dependent variable (Y1). The photodegradation efficiency $\left(\%, \mathrm{Y}_{1}\right)$ was selected as a dependent factor. The statistical experimental data were analysed using the Design-Expert ${ }^{\circledR}$ Software (Vers.-8.0.7.1, Stat-Ease Inc., Minneapolis).

\subsection{Preparation of thick films}

In this study, a thick film of PPy/1-D ZnO nanocomposite was used as a gas sensing module. The thixotropic pastes [38-41] were formulated by mixing the resulting fine powders with a solution of ethyl cellulose (a temporary binder) in a mixture of organic solvents such as butyl cellulose, butyl carbitol acetate and turpineol. The ratio of inorganic to organic part was kept at $75: 25$ in formulating the pastes. The thixotropic pastes were screen printed onto glass substrates in desired patterns. The films prepared were fired at $90^{\circ} \mathrm{C}$ for $2 \mathrm{~h}$. Thus thick films of PPy/1-D ZnO nanocomposite were prepared. Silver contacts were made by vacuum evaporation for electrical and gas sensing measurements.

\subsection{Gas sensor system}

Gas sensing was performed by static gas sensing system, which comprises of $15 \mathrm{~L}$ glass gas chamber containing an electric heating plate, a thermocouple and a temperature controller. Required temperature conditions for sensing were maintained by heater resting on the base plate. The temperature was tuned by means of varying current through heater with adjustable ON and OFF time interval. Electrical connections and gas inlet were provided through ports at the base plate. The necessary gas concentration in the glass dome was achieved by injecting a required quantity of gas by means of a syringe. The current change was recorded by using a digital pico-ammeter keeping constant voltage. The sensing measurements were performed by exposing the thick films

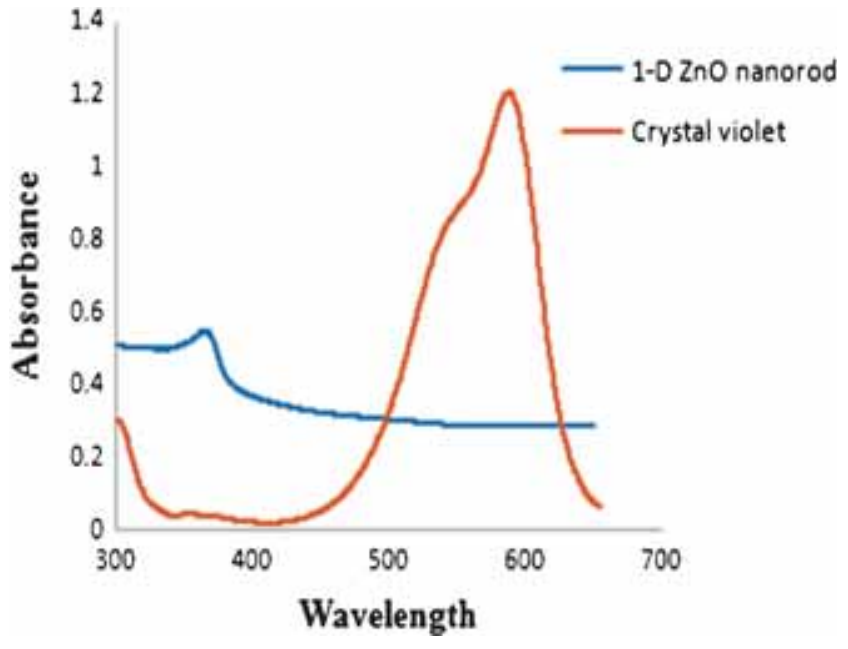

Figure 1. UV-Vis absorption spectra of 1-D $\mathrm{ZnO}$ nanorods and crystal violet.

of nanocomposite to gases in a closed glass dome $(15 \mathrm{~L})$ to mimic atmospheric condition. The electrical conductivity of a thick film in air and in the presence of gas was used to evaluate the sensor response as [38],

$$
\text { Gas response }(s)=\left(G_{\mathrm{a}}-G_{\mathrm{g}}\right) / G_{\mathrm{g}},
$$

where $G_{\mathrm{a}}$ is the conductance in the air and $G_{\mathrm{g}}$ the conductance upon exposure to test gas. Response time (RST) was defined as the time necessary to attain the $90 \%$ of the maximum increase in conductance subsequent to exposure of the sensing film to a gas, whereas recovery time (RCT) as the time needed to regain $90 \%$ of the maximum conductance in the air.

\section{Results and discussion}

\subsection{UV-Vis absorption}

The UV-Vis absorption spectra of synthesized 1-D ZnO nanorods and crystal violet are illustrated in figure 1 . The precursor of $\mathrm{ZnO}$ synthesis shows the absorption spectra at $285.65 \mathrm{~nm}$ of zinc sulphate heptahydrate in the reported literature [42], after complete precipitation reaction with $\mathrm{NaOH}$, it shows the absorption maxima at $361.5 \mathrm{~nm}$ of synthesized 1-D ZnO nanorods shown in figure 1. Similarly, crystal violet 
showed the absorption maxima at $584.1 \mathrm{~nm}$. The photocatalytic property involves the electron transition from the valence band to the conduction band resultant to the direct band gap of 1-D $\mathrm{ZnO}$ nanorods. The band gap energy of the 1-D $\mathrm{ZnO}$ nanords was determined by the following equation [43],

$$
E_{\mathrm{g}}=h c / \lambda \text {, }
$$

where $h=4.135 * 10^{-15} \mathrm{eVs}, c=2.99 * 10^{8} \mathrm{~m} \mathrm{~s}^{-1}$ and $\lambda=$ $361.5 \mathrm{~nm}$ for 1-D $\mathrm{ZnO}$ nanorod synthesized by precipitation method. Applying above equation, the band gap energy of the synthesized 1-D ZnO nanorods was found to be $3.42 \mathrm{eV}$.

\subsection{Field emission-scanning electron microscopy analysis}

Field emission-scanning electron microscopy (FE-SEM) was performed to examine the surface characteristics of 1-D ZnO nanorods and PPy/1-D ZnO nanocomposite. Figure 2a shows uniform surface morphology of the 1-D ZnO nanorod with an average diameter of $30-50 \mathrm{~nm}$. The synthesized 1-D $\mathrm{ZnO}$ nanorods were found to be isolated and free flowing in nature. The morphology of 1-D $\mathrm{ZnO}$ nanorods was changed after polymerization of pyrrole as shown in figure $2 \mathrm{~b}$. It was clear from the image that the 1-D $\mathrm{ZnO}$ nanorods were uniformly coated by polypyrrole. This revealed that the 1-D $\mathrm{ZnO}$ nanorods interact with PPy. The large area and uniform morphology of PPy/1-D ZnO nanocomposite are appropriate for gas sensing application [44].

\subsection{Fourier transform infrared spectroscopy analysis}

The Fourier transform infrared spectroscopy (FT-IR) spectra of 1-D ZnO nanorod and PPy/1-D ZnO nanocomposite material are shown in figure 3. The IR spectrum of $\mathrm{ZnO}$ nanorods (figure 3a) showed the principle peaks at 3364.63 and $1553.71 \mathrm{~cm}^{-1}$ and are due to the bending and stretching vibration of a hydroxyl group $(-\mathrm{OH})$. The peak situated at $485.11 \mathrm{~cm}^{-1}$ corresponds to the stretching vibration of $\mathrm{Zn}-\mathrm{O}$ bond. The peaks at 1478 and $1558 \mathrm{~cm}^{-1}$ are assigned to stretching mode of $\mathrm{C}=\mathrm{C}$ and $\mathrm{C}-\mathrm{C}$ in pyrrole ring are disappeared [45] and wide peak appears at $1536.35 \mathrm{~cm}^{-1}$ in the PPy/1-D ZnO nanocomposite (figure 3b). The broadening and change in peak position indicate that there is a strong chemical interaction between PPy and 1-D ZnO nanorod.

\section{$3.4 \quad X$-ray diffraction}

The XRD spectra of 1-D ZnO nanorod and PPy/1-D ZnO nanocomposite are shown in figure 4 . From figure $4 a$, the $\mathrm{XRD}$ pattern of $\mathrm{ZnO}$ nanorods shows the characteristic peaks at scattering angles $(2 \theta)$ of $30.78,34.29,35.34,46.72,54.74$, 62.09 and $66.20^{\circ}$ are correspond to the diffractions from (100), (002), (101), (102), (110), (103) and (112) crystal planes, respectively [21]. The sharp diffraction peaks implies the crystalline nature and no other peaks of impurity are observed in pure $\mathrm{ZnO}$ hexagonal (wurzite) structure. The average crystallite size of 1-D $\mathrm{ZnO}$ nanorods is calculated by using Scherrer equation was found to be $20.13 \mathrm{~nm}$. The XRD pattern of PPy/1-D ZnO nanocomposite is shown in figure $4 \mathrm{~b}$. This pattern exhibits a broad peak at a lower diffraction angle $2 \theta=23.9$, which implies their amorphous nature. This broadening of peak can be ascribed to the scattering of the PPy around 1-D ZnO nanorods [45].

\subsection{Mechanism of photodegradation of crystal violet}

In general, the UV light absorbed capacity of 1-D $\mathrm{ZnO}$ nanorods is more than any other nanostructures. This causes
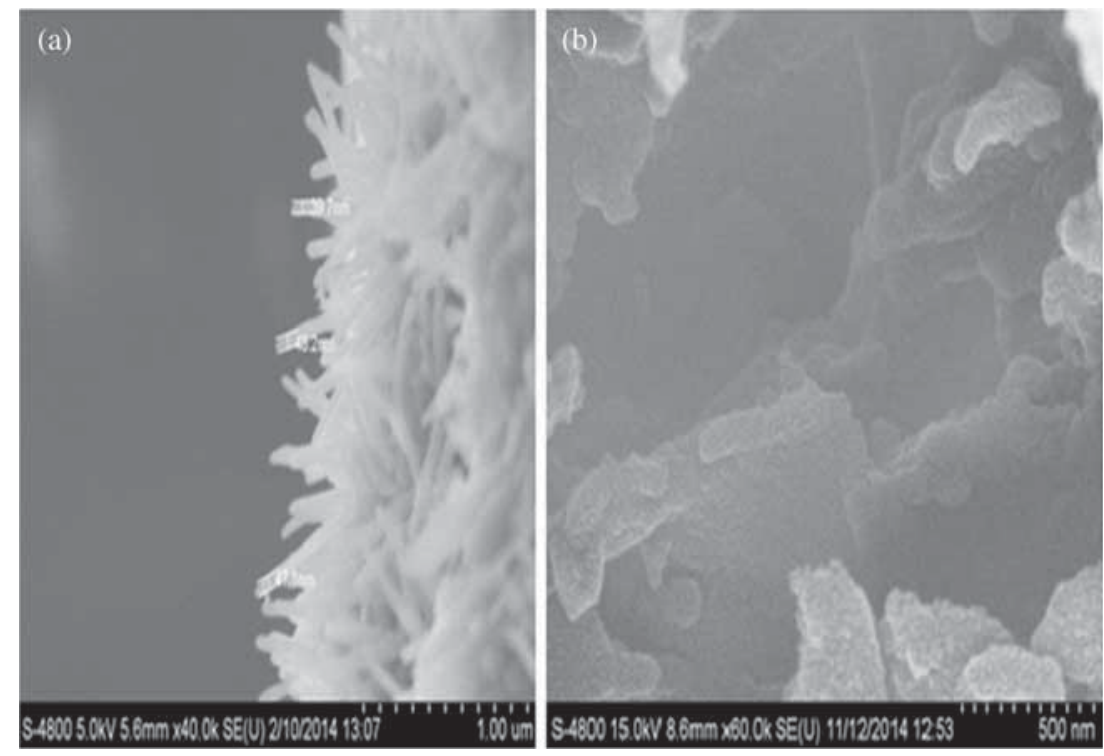

Figure 2. FESEM images of (a) 1-D $\mathrm{ZnO}$ nanorods and (b) PPy/1-D ZnO nanocomposites. 


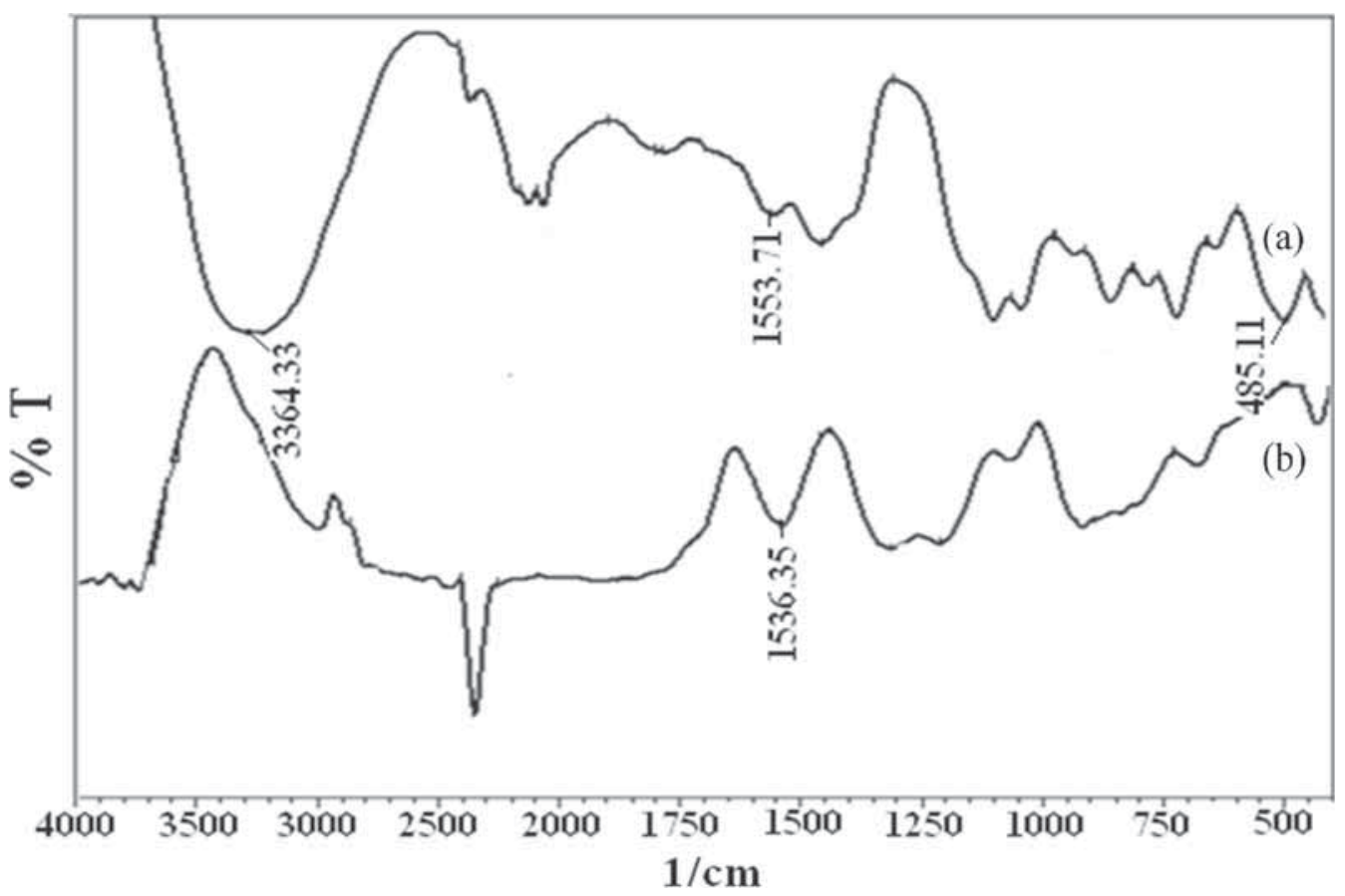

Figure 3. FTIR spectra of (a) 1-D ZnO nanorods and (b) PPy/1-D ZnO nanocomposites.

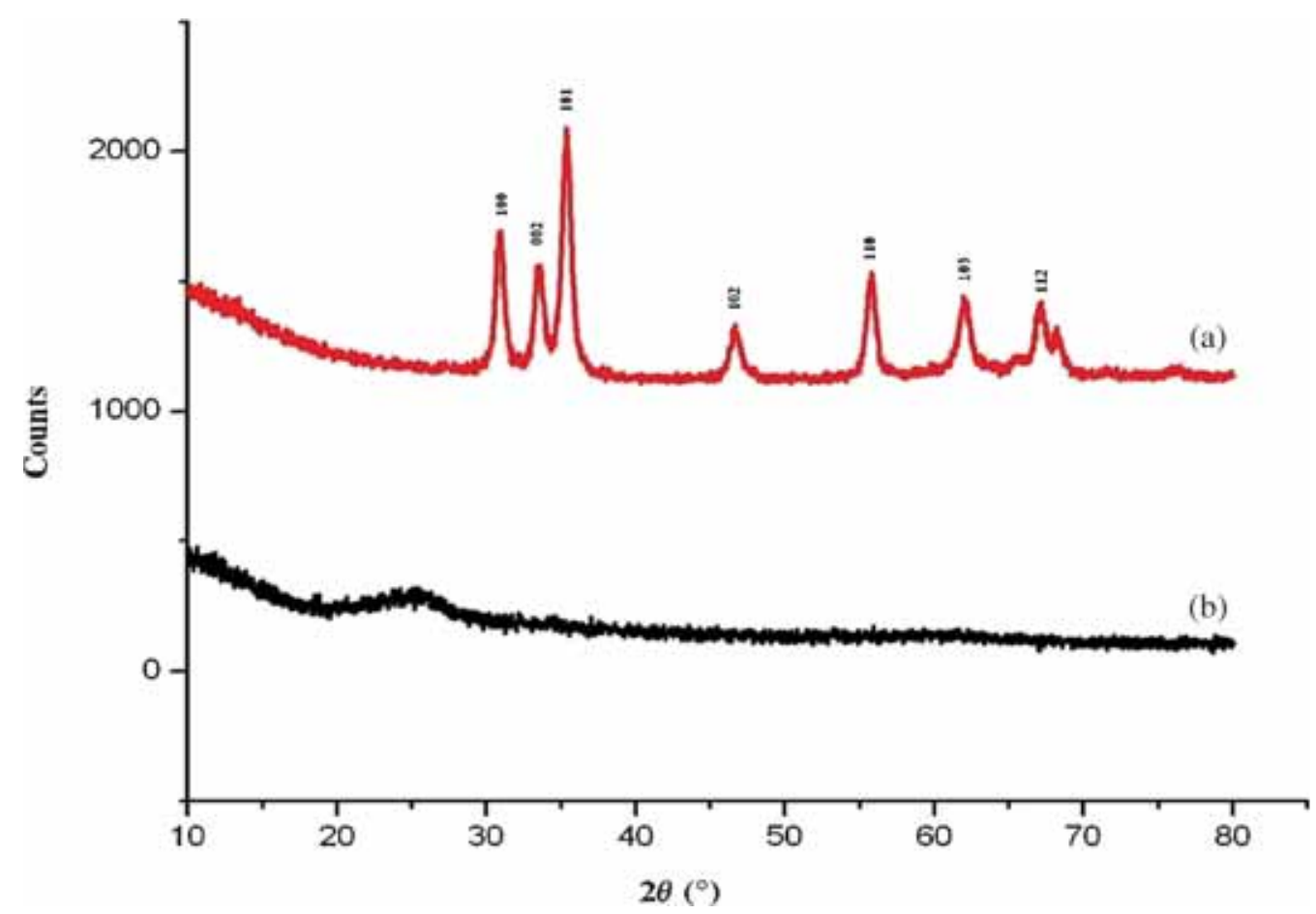

Figure 4. XRD pattern of (a) 1-D ZnO nanorods and (b) PPy/1-D ZnO nanocomposites.

the production of more electrons-hole $\left(\mathrm{e}^{-} / \mathrm{h}^{+}\right)$pairs of conduction and valence band. This electron-hole pair plays an important role in the redox reaction. The highly oxidizing valence band holes react with $\mathrm{H}_{2} \mathrm{O}$ to produce the hydroxyl radicals and strongly reducing conduction band electrons produce the $\mathrm{O}_{2}^{-}$molecules [46,47]. The hydroxyl radicals formed on the $\mathrm{ZnO}$ surface are strong oxidizing agents, which lead to the photodegradation of crystal violet. 
The photodegration reaction steps of crystal violet at the 1-D $\mathrm{ZnO}$ nanorod surface is described as follows [32],

$$
\begin{aligned}
& \mathrm{ZnO}+\mathrm{hv} \rightarrow \mathrm{e}_{\mathrm{CB}}^{-}+\mathrm{h}_{\mathrm{VB}}^{+} \\
& \mathrm{h}_{\mathrm{VB}}^{+}+\mathrm{H}_{2} \mathrm{O} \rightarrow{ }^{\circ} \mathrm{OH}+\mathrm{H}^{+} \\
& \mathrm{CV}+\cdot \mathrm{OH} \rightarrow \text { degradation product } \\
& \mathrm{e}_{\mathrm{CB}}^{-}+\mathrm{O}_{2} \rightarrow \mathrm{O}_{2}^{-} \\
& \mathrm{CV}+\mathrm{O}_{2}^{-} \rightarrow \text { degradation product } \\
& \mathrm{e}_{\mathrm{CB}}^{-}+\mathrm{h}_{\mathrm{VB}}^{+} \rightarrow \text { heat recombination. }
\end{aligned}
$$

3.6 Statistical analysis of photodegradation efficiency (\%)

$3^{3}$ full-factorial experimental designs were used to evaluate the effect of independent variables on the dependent variables. Concentration of dye $(A)$, concentration of catalyst $(B)$ and reaction time $(C)$ were selected as independent variables, while photodegradation efficiency $(\%, \mathrm{Y} 1)$ was selected as a dependent variable. The effect of independent variables on dependent variable was investigated by deriving polynomial equation and contour plots. The photodegradation efficiency from different experimental runs is reported in table 2. Diagnostics case statistics for various response variables are shown in table 3. The polynomial equation obtained for (Y1),

$$
\begin{aligned}
\mathrm{Y} 1 & =64.41-17.28 A-0.16 B+1.26 C+0.99 A^{2} \\
& -8.63 B^{2}-3.97 C^{2}+2.18 A B-0.016 A C+0.13 B C .
\end{aligned}
$$

\begin{tabular}{|c|c|c|c|}
\hline Batch no. & Actual value & Predicted value & Residual \\
\hline $\mathrm{F} 1$ & 74.59 & 73.86 & 0.73 \\
\hline $\mathrm{F} 2$ & 59.91 & 60.51 & -0.60 \\
\hline F3 & 52.74 & 54.97 & -2.23 \\
\hline $\mathrm{F} 4$ & 53.50 & 54.97 & -1.47 \\
\hline F5 & 54.00 & 54.97 & -0.97 \\
\hline F6 & 34.80 & 45.94 & -11.14 \\
\hline F7 & 0.00 & -7.64 & 7.64 \\
\hline F8 & 0.00 & 4.24 & -4.24 \\
\hline F9 & 75.44 & 66.74 & 8.70 \\
\hline F10 & 54.50 & 54.97 & -0.47 \\
\hline F11 & 67.90 & 63.93 & 3.97 \\
\hline F12 & 52.74 & 54.97 & -2.23 \\
\hline F13 & 92.95 & 93.96 & -1.01 \\
\hline F14 & 72.60 & 69.94 & 2.66 \\
\hline F15 & 0.00 & -6.71 & 6.71 \\
\hline F16 & 0.00 & -1.59 & 1.59 \\
\hline F17 & 0.00 & 6.12 & -6.12 \\
\hline F18 & 63.87 & 61.38 & 2.49 \\
\hline F19 & 97.13 & 105.42 & -8.29 \\
\hline $\mathrm{F} 20$ & 92.53 & 98.70 & -6.17 \\
\hline $\mathrm{F} 21$ & 53.62 & 55.66 & -2.04 \\
\hline $\mathrm{F} 22$ & 93.68 & 90.22 & 3.46 \\
\hline $\mathrm{F} 23$ & 84.40 & 69.55 & 14.85 \\
\hline $\mathrm{F} 24$ & 54.75 & 54.97 & -0.22 \\
\hline F25 & 38.78 & 47.43 & -8.65 \\
\hline F26 & 88.00 & 82.79 & 5.21 \\
\hline F27 & 0.00 & -3.22 & 3.22 \\
\hline F28 & 0.00 & 3.89 & -3.89 \\
\hline F29 & 89.19 & 84.52 & 4.67 \\
\hline F30 & 0.00 & -0.12 & 0.12 \\
\hline F31 & 93.71 & 94.96 & -1.25 \\
\hline F32 & 0.00 & 5.02 & -5.02 \\
\hline
\end{tabular}

A positive value in the above equation represents the synergistic effect of the independent variable, while a negative

Table 2. Photodegradation efficiency (\%, Y1).

\begin{tabular}{lrrrr}
\hline $\begin{array}{l}\text { Batch } \\
\text { no. }\end{array}$ & $\begin{array}{c}\text { Conc. of } \\
\text { dye (ppm) }\end{array}$ & $\begin{array}{c}\text { Conc. of } \\
\text { catalyst }\left(\mathrm{g}^{-1}\right)\end{array}$ & $\begin{array}{r}\text { Reaction } \\
\text { time (min) }\end{array}$ & $\begin{array}{r}\text { Photodegradation } \\
\text { efficiency }(\%)\end{array}$ \\
\hline F1 & 7.50 & 0.10 & 120.00 & 74.59 \\
F2 & 7.50 & 1.00 & 60.00 & 59.91 \\
F3 & 7.50 & 0.50 & 60.00 & 52.74 \\
F4 & 7.50 & 0.50 & 60.00 & 53.50 \\
F5 & 7.50 & 0.50 & 60.00 & 54.00 \\
F6 & 10.00 & 0.10 & 60.00 & 34.80 \\
F7 & 7.50 & 0.10 & 0.00 & 0.00 \\
F8 & 10.00 & 1.00 & 0.00 & 0.00 \\
F9 & 5.00 & 0.50 & 60.00 & 75.44 \\
F10 & 7.50 & 0.50 & 60.00 & 54.50 \\
F11 & 10.00 & 1.00 & 60.00 & 67.90 \\
F12 & 7.50 & 0.50 & 60.00 & 52.74 \\
F13 & 7.50 & 1.00 & 120.00 & 92.95 \\
F14 & 10.00 & 0.10 & 120.00 & 72.60 \\
F15 & 10.00 & 0.10 & 0.00 & 0.00 \\
F16 & 7.50 & 1.00 & 0.00 & 0.00 \\
F17 & 5.00 & 0.50 & 0.00 & 0.00 \\
F18 & 5.00 & 0.10 & 60.00 & 63.87 \\
F19 & 5.00 & 1.00 & 120.00 & 97.13 \\
F20 & 5.00 & 0.50 & 120.00 & 92.53 \\
F21 & 10.00 & 0.50 & 60.00 & 53.62 \\
F22 & 5.00 & 0.10 & 120.00 & 93.68 \\
F23 & 5.00 & 1.00 & 60.00 & 84.40 \\
F24 & 7.50 & 0.50 & 60.00 & 54.75 \\
F25 & 7.50 & 0.10 & 60.00 & 38.78 \\
F26 & 10.00 & 0.50 & 120.00 & 88.00 \\
F27 & 7.50 & 0.50 & 0.00 & 0.00 \\
F28 & 5.00 & 0.10 & 0.00 & 0.00 \\
F29 & 7.50 & 0.50 & 120.00 & 89.19 \\
F30 & 10.00 & 0.50 & 0.00 & 0.00 \\
F31 & 10.00 & 1.00 & 120.00 & 93.71 \\
F32 & 5.00 & 1.00 & 0.00 & 0.00 \\
\hline & & & & \\
\hline
\end{tabular}

Table 3. Diagnostic case statistics of response variable (Y1). 
Table 4. Summary of regression analysis for response Y1.

\begin{tabular}{lcccccc}
\hline Models & $R^{2}$ & Adjusted $R^{2}$ & Predicted $R^{2}$ & Std. Dev. & Press & Remarks \\
\hline Response Y1 & & & & & & \\
Linear & 0.9265 & 0.9187 & 0.9000 & 10.14 & 3917.17 & $\ldots \ldots \ldots$ \\
2FI & 0.9340 & 0.9181 & 0.8793 & 10.17 & 4731.25 & $\ldots \ldots \ldots$ \\
Quadratic & 0.9764 & 0.9667 & 0.9411 & 6.49 & 2309.91 & Suggested \\
Cubic & 0.9943 & 0.9882 & 0.9643 & 3.86 & 1398.85 & $\ldots \ldots \ldots$ \\
\hline Y1 $=64.41-17.28 \mathrm{~A}-0.16 \mathrm{~B}+1.26 \mathrm{C}+0.99 \mathrm{~A}^{2}-8.63 \mathrm{~B}^{2}-3.97 \mathrm{C}^{2}+2.18 \mathrm{AB}-0.016 \mathrm{AC}+$ \\
0.13BC.
\end{tabular}

Table 5. ANOVA of model for Y1.

\begin{tabular}{lrrrrr}
\hline & & & & & \\
Source & DF & Sum of squares & $\begin{array}{c}\text { Mean } \\
\text { square }\end{array}$ & F-value & $P$-value \\
\hline Model for Y1 & 9 & 38260.17 & 4251.13 & 101.07 & $<0.0001$ \\
A & 1 & 498.08 & 498.08 & 11.84 & $<0.0023$ \\
B & 1 & 769.37 & 769.37 & 18.29 & 0.0003 \\
C & 1 & 35192.87 & 35192.87 & 836.71 & $<0.0001$ \\
A $^{2}$ & 1 & 277.39 & 277.39 & 6.59 & 0.0175 \\
B $^{2}$ & 1 & 21.21 & 21.21 & 0.50 & 0.4851 \\
C $^{2}$ & 1 & 1467.61 & 1467.61 & 34.89 & $<0.0001$ \\
AB & 1 & 72.65 & 72.65 & 1.73 & 0.2023 \\
AC & 1 & 70.23 & 70.23 & 1.67 & 0.2097 \\
BC & 1 & 149.01 & 149.01 & 3.54 & 0.0731 \\
\hline
\end{tabular}

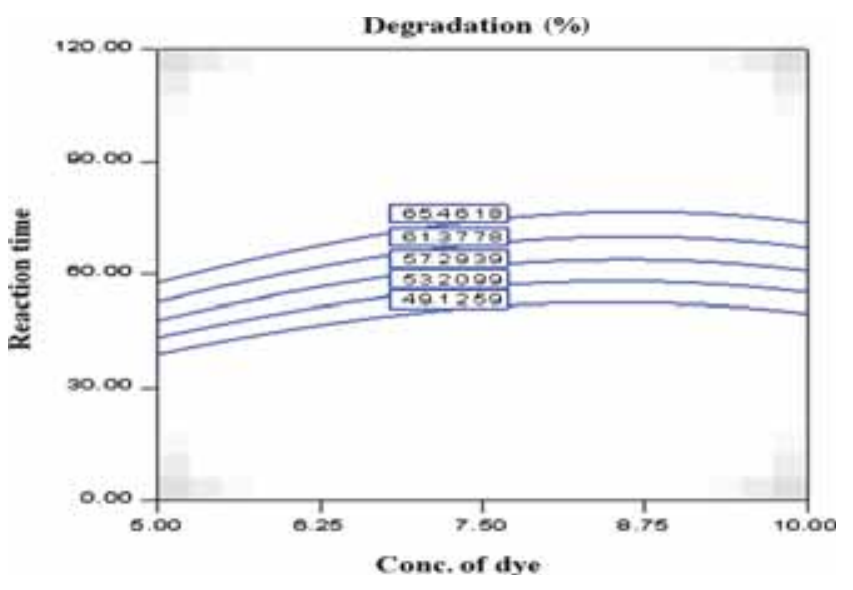

Figure 5. Effect of individual variables (conc. of dye and reaction time) on degradation efficiency (\%).

value represents the inverse relationship (antagonistic effect) $[48,49]$. -17.28 represents the antagonistic effect of independent factor $A$ (concentration of dye) on photodegradation efficiency $(\%, Y 1)$. While +1.26 represents the synergistic effect of independent factor $C$ (reaction time) on photodegradation efficiency $(\%, Y 1)$. The suggested model for the Y1 was found to be quadratic as per design expert software with $R^{2}=0.9764$, which is shown in table 4 . The $P$-value for the Y1 model was found to be $<0.0001$, which clearly indicates the model is statistically significant

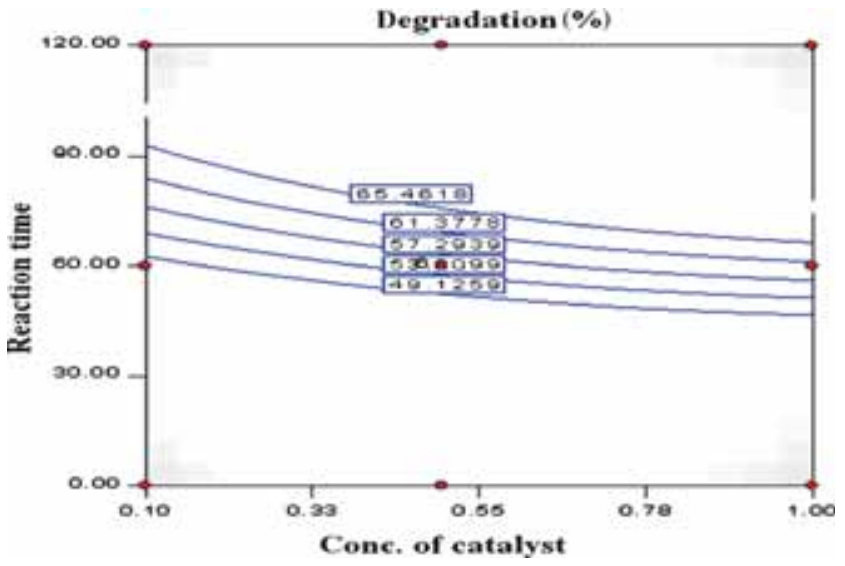

Figure 6. Effect of individual variables (conc. of catalyst and reaction time) on degradation efficiency (\%).

$(P<0.05$ indicates that model terms are significant). The results showed that the photodegradation efficiency of $\mathrm{CV}$ dye was affected by the independent variables. Table 5 shows the ANOVA of model for Y1. The effect of $A(P<0.0023)$, $B(P=0.0003), C(P=0.0001)$ and $C^{2}(P=0.0001)$ were found to be statistically significant. The interaction terms $A B$ in $\mathrm{Y} 1$ show how photodegradation efficiency changes when 2 variables are simultaneously changed. The model Fvalue for $\mathrm{Y} 1$ was 101.07, which implies that the model was significant. To analyse the effect of independent variables on the dependent variable, a 2D contour plot was constructed for the photodegradation efficiency of CV dye. From the contour plot (figure 5), it was observed that the photodegradation efficiency of $\mathrm{CV}$ dye was increased from lower level to a higher level of dye concentration $(A)$ and reaction time $(C)$. The same type of results was observed in the case of catalyst concentration $(B)$ and reaction time $(C)$ from contour plot (figure 6). From contour plot (figure 7), it could be concluded that when the concentration of the catalyst $(B)$ was kept constant and the concentration of dye $(A)$ was increased, the photodegradation efficiency of CV dye decreases. This might be due to an increase in concentration of dye which decreases the path length of photons that arrive in the solution, therefore only few photons reached the catalyst surface, which decreases the production rate of hydroxyl and superoxide radical formation [50]. Also, when the concentration of 
dye $(A)$ was kept constant and concentration of catalyst was increased, the photodegradation efficiency of crystal violet increases. This may be due to an increase in concentration of catalyst, increases the active sites available on photocatalyst surface for the reaction, which successively increases the production rate of hydroxyl and superoxide radical formations $[32,50]$. The degradation performance of the nanomaterials was studied by various scientists and its performance in terms of \% degradation and time interval was compared with the present study, shown in table 6 .

\subsection{Gas sensing mechanism}

The mechanism for gas detection in nanomaterials is based on reactions that occur at the active sites of the sensor surface, resulting in a change in the concentration of adsorbed oxygen $\left(\mathrm{O}^{-}\right)$ions. Oxygen ions adsorb onto the material's surface, capture electrons from the bulk, building a potential barrier of depth $\delta$ that decreases the channel width Lc of passage of electrons through a nanoparticle of diameter $D$ and hence, decrease in electron movement and the conductivity occurs [51].

$$
\mathrm{Lc}=D-2 \delta \text {. }
$$

If the particle size is reduced up to nanometer level $(<100 \mathrm{~nm})$, the channel width would be almost blocked and the initial resistance of the sensor would be infinitely high in air ambient. On exposure, the target gas would consume oxygen atoms to oxidize, liberating electrons behind it on the surface. Desorption of oxygen from the surface of the sensor would decrease the potential barrier height, which broadens the channel width for migration of electrons. Thus, nanoscaled materials offer the grain sizes where the depletion layer has about the same dimensions as the particle radii. The charge transfer is, therefore, predominantly grain-controlled. When reactive gases combine with this oxygen, the barrier height is reduced, broadening the passage of electrons and hence, conductivity increases. This change in conductivity is directly related to the amount of a specific gas present in the environment, resulting in a quantitative determination of gas presence and concentration. To maximize the opportunities for surface reactions, a high ratio of surface area to volume is needed. As an inverse relationship exists between surface area and particle size, nanoscale materials, which exhibit very high surface area, are highly desirable.

\subsection{Gas sensing measurements}

3.8a Selectivity: Figure 8 shows gas selectivity performance of PPy/1-D $\mathrm{ZnO}$ nanocomposites at room temperature. It can be seen that PPy/ZnO-15 is highly selective towards $\mathrm{NH}_{3}$ gas. In addition, the decrease in selectivity to ammonia was observed to increase the mass $\%$ of $1-\mathrm{D} \mathrm{ZnO}$ nanocomposite.

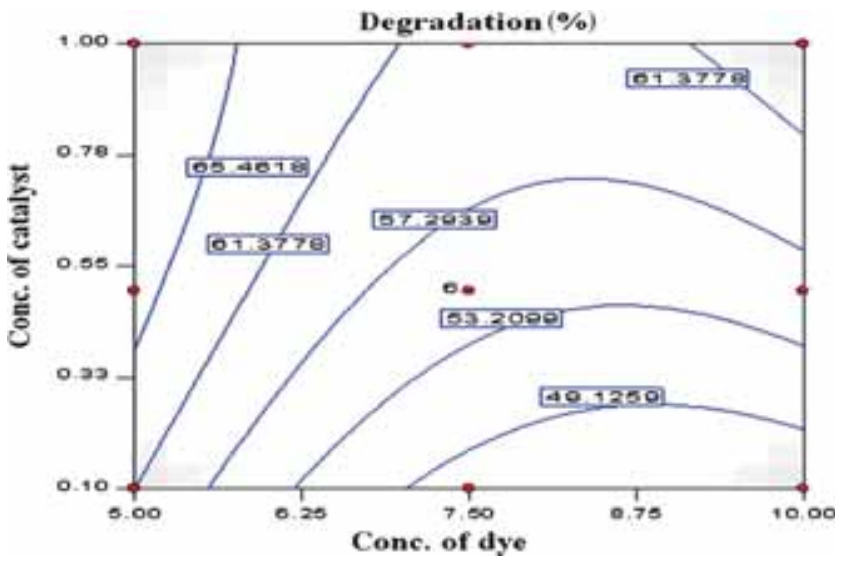

Figure 7. Effect of individual variables (conc. of dye and conc. of catalyst) on degradation efficiency (\%).

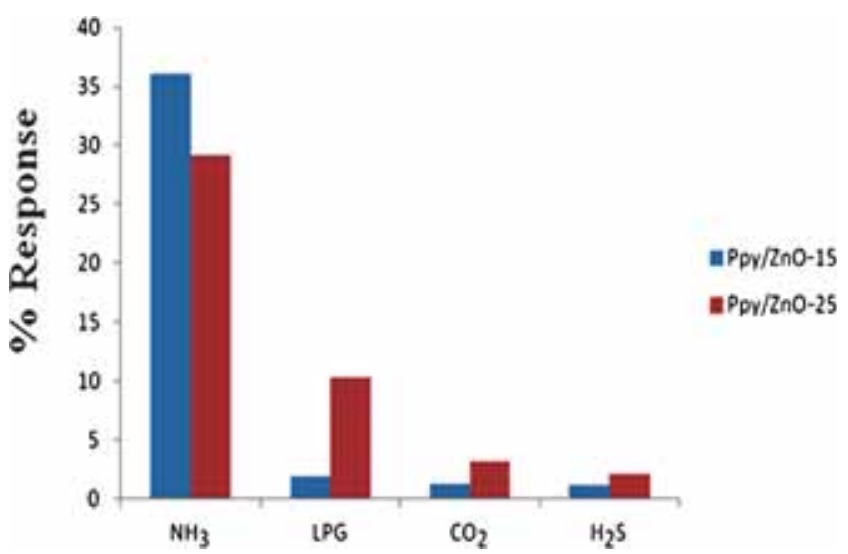

Figure 8. Selectivity performance of $\mathrm{PPy} / 1-\mathrm{D} \mathrm{ZnO}$ nanocomposite.

Table 6. Comparative degradation performance of the nanomaterials.

\begin{tabular}{llccc}
\hline Catalyst & $\begin{array}{l}\text { Degradation } \\
\text { material }\end{array}$ & Source & Degradation (\%) & $\begin{array}{c}\text { Time interval } \\
\text { (min) }\end{array}$ \\
\hline $\mathrm{ZnO} \mathrm{[35]}$ & Crystal violet & UV light & 96 & 80 \\
$\mathrm{ZnO}$ [52] & Reactive red 120 & Solar light & 100 & 60 \\
$\begin{array}{l}\text { 1-D ZnO } \\
\text { (present study) }\end{array}$ & Crystal violet & UV light & 97.13 & 120 \\
$\mathrm{TiO}_{2}[53]$ & Crystal violet & UV light & 100 & 30 \\
\hline
\end{tabular}




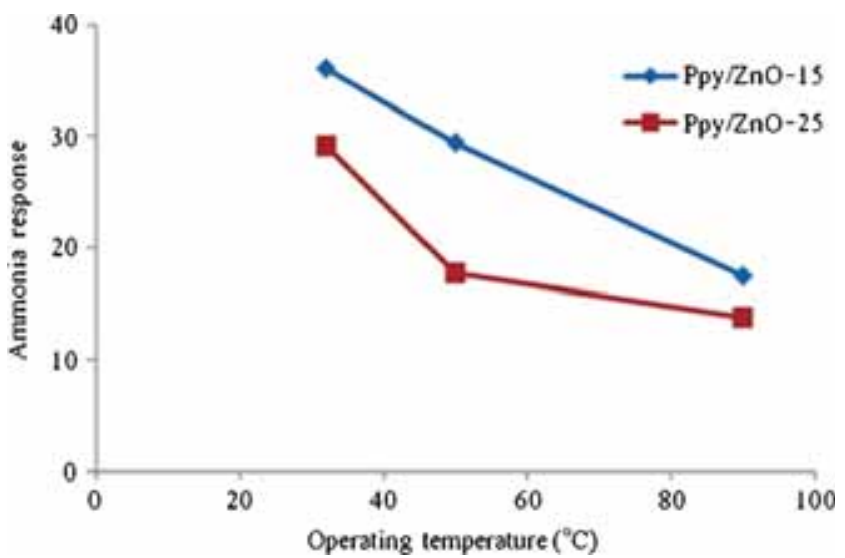

Figure 9. Variation of ammonia response with operating temperatures.

3.8b Effect of operating temperature: For the gas sensing study, we prepare two nanocomposite PPy/ZnO-15 and $\mathrm{PPy} / \mathrm{ZnO}-25$, where 15 and 25 are the mass percentages of 1-D $\mathrm{ZnO}$ nanorods in the nanocomposite. The response of PPy/1-D ZnO nanocomposite thick films to $1000 \mathrm{ppm}$ of $\mathrm{NH}_{3}$, as a function of operating temperature, is shown in figure 9. It is observed from the figure that the gas response is highest at room temperature and decreases with operating temperature. The sample, $\mathrm{PPy} / \mathrm{ZnO}-15$ showed the highest response to $1000 \mathrm{ppm} \mathrm{NH}_{3}$ at room temperature $\left(32^{\circ} \mathrm{C}\right)$. The response to ammonia could be attributed to the surface active sites to sense ammonia gas.

3.8c Effect of gas concentration (ppm): The change in response of $\mathrm{PPy} / \mathrm{ZnO}$ thick film with variation in gas concentration is shown in figure $10 \mathrm{a}$ and $\mathrm{b}$. The highest

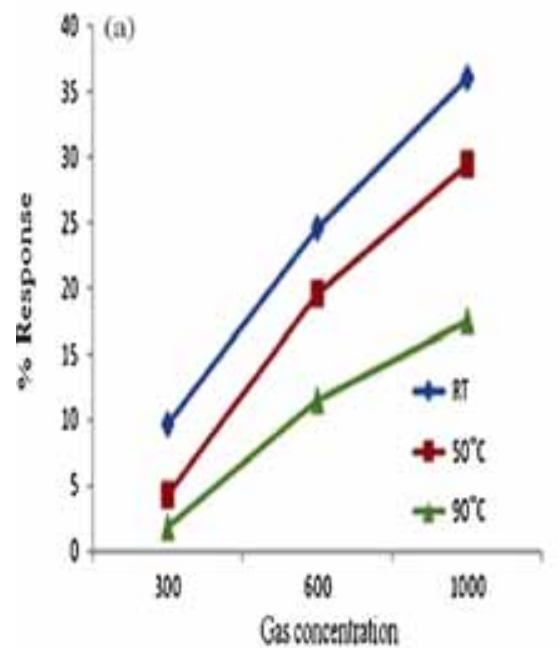

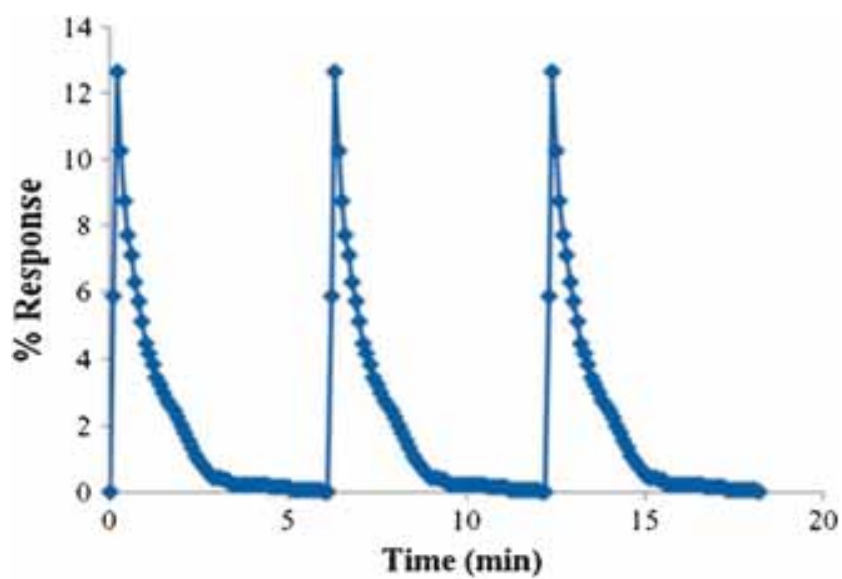

Figure 11. Response and recovery profile of $\mathrm{PPy} / \mathrm{ZnO}-15$ nanocomposite.

response recorded were 36.1 and $29.19 \%$ for $1000 \mathrm{ppm}$ of $\mathrm{NH}_{3}$ at room temperature for PPy/ZnO-15 and PPy/ZnO25 , respectively. It was observed that the increase in $\mathrm{ZnO}$ doping results in a decrease in the response of sensing film. Response of sensing film to $\mathrm{NH}_{3}$ was found to be decreased with increase in temperature. However, interestingly, recovery time was found to be decreased at elevated temperature, although at $90^{\circ} \mathrm{C}$ only $\sim 89 \%$ of original conductance was recovered.

3.8d Response-recovery profile of the sensor: Recovery time of PPy/ZnO-15 sensing film was 2, 6 and $10 \mathrm{~min}$ for 300,600 and $1000 \mathrm{ppm}$ of $\mathrm{NH}_{3}$, respectively, at $50^{\circ} \mathrm{C}$ after introduction of clean air. The reproducing capability of nanocomposite was investigated by exposing it to 300 ppm at $50^{\circ} \mathrm{C}$ and then blowing air repeatedly for three

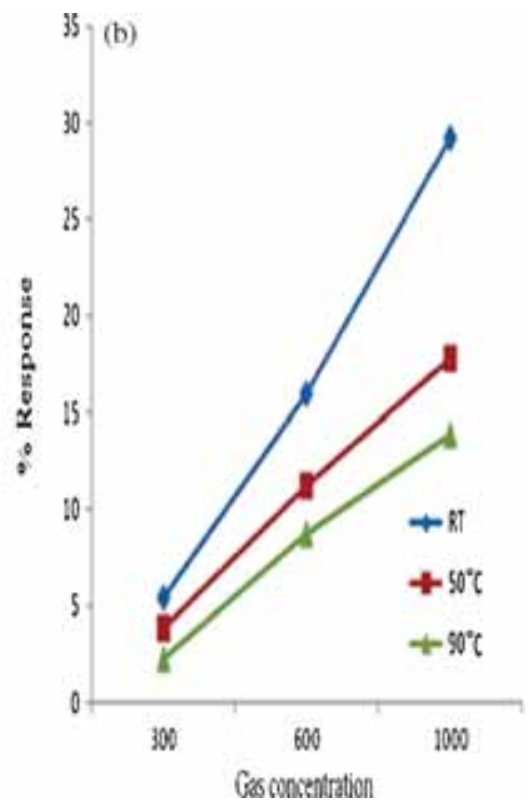

Figure 10. Response of (a) PPy/ZnO-15 and (b) PPy/ZnO-25 nanocomposites to ammonia at different gas concentrations. 
Table 7. Comparative gas sensing performance of the nanocomposites/nanomaterials.

\begin{tabular}{llccc}
\hline $\begin{array}{l}\text { Nanomaterial/ } \\
\text { nanocomposite }\end{array}$ & \multicolumn{1}{c}{ Gas } & $\begin{array}{c}\text { Sensitivity } \\
(\%)\end{array}$ & $\begin{array}{c}\text { Response } \\
\text { time }\end{array}$ & Recovery time \\
\hline PPy/ZnO [54] & $\mathrm{NO}_{2}(100 \mathrm{ppm})$ & 38 & $2-4 \mathrm{~min}$ & $24 \mathrm{~h}$ \\
$\mathrm{PPy} / \mathrm{ZnO}[45]$ & $\mathrm{LPG}^{(1400 \mathrm{ppm})}$ & 32.5 & $3.5-4 \mathrm{~min}$ & $40 \mathrm{~min}$ \\
$\mathrm{ZnO}$ nanorod [55] & $\mathrm{NH}_{3}(50 \mathrm{ppm})$ & 97.7 & $14 \mathrm{~s}$ & $25 \mathrm{~s}$ \\
$\begin{array}{l}\text { 1-D ZnO nanorod/PPy } \\
\text { (present study) }\end{array}$ & $\mathrm{NH}_{3}(1000 \mathrm{ppm})$ & 36.1 & $2-5 \mathrm{~s}$ & $10 \mathrm{~min}$ \\
PPy [56] & $\mathrm{NH}_{3}(25 \mathrm{ppm})$ & 16 & $20 \mathrm{~s}$ & $15 \mathrm{~min}$ \\
\hline
\end{tabular}

times. It was observed from figure 11 that the PPy/ZnO15 nanocomposite showed excellent recovery. The gas sensing performance of the nanocomposites/nanomaterials was studied by various scientists and its performance in terms of sensitivity, response and recovery time was compared with present study as shown in table 7 .

\section{Conclusion}

1-D $\mathrm{ZnO}$ nanorods were successfully synthesized by surfactant-assisted precipitation method using $\mathrm{ZnSO} 4 \cdot 7 \mathrm{H}_{2} \mathrm{O}$ as precursor, which serve as photocatalyst for the degradation of crystal violet dye. $3^{3}$ full-factorial experimental design was used to evaluate the effect of independent variables on the photodegradation efficiency (\%). The photocatalytic activity of synthesized 1-D $\mathrm{ZnO}$ nanorods shows very rapid degradation of crystal violet dye with the degradation rate of $97.13 \%$ was achieved by run F19 using 5 ppm concentration of dye, $1 \mathrm{~g} \mathrm{l}^{-1}$ concentration of catalyst and reaction time interval of $120 \mathrm{~min}$. This might be due to an increase in concentration of catalyst, increases the active sites available on photocatalyst surface for the reaction. However, the catalyst concentration less than $1 \mathrm{~g} \mathrm{l}^{-1}$ restricts the degradation rate of crystal violet at $5 \mathrm{ppm}$ of dye concentration. The present result suggests that the $3^{3}$ full-factorial experimental design was reliable for optimizing the degradation rate of crystal violet by the 1-D $\mathrm{ZnO}$ nanorods. On the other hand, PPy/1-D ZnO nanocomposite was successfully prepared by in situ polymerization of pyrrole monomer. The synthesized PPy/ZnO-15 nanocomposite showed high sensitivity and selectivity towards $\mathrm{NH}_{3}(36.1 \%)$ at room temperature. During study, it was found that increase in concentration of 1-D $\mathrm{ZnO}$ in nanocomposite resulted in a decrease in sensitivity as well as recovery time. Owing to high sensitivity and good recovery time at room temperature, the proposed nanocomposite holds great promises in the gas sensor field.

\section{Acknowledgement}

We are grateful to Technical Education Quality Improvement Programme (TEQIP-II) for providing financial assistance to carry out this research work.

\section{References}

[1] Tian F, Zhao Y, Liu Y, Cao H, Zhao J and Lu X 2014 Mater. Lett. 1198

[2] Okada T, Kawashima K and Nakata Y 2006 Thin Solid Films 506274

[3] Rao C, Kulkarni G, Thomas P and Edwards P 2000 Chem. Soc. Rev. 29275

[4] Deng Z, Chen M, Gu G and Wu L 2008 J. Phys. Chem. B 11216

[5] Yang S and Park C 2008 Nanotechnology 194

[6] Krishnakumar T, Jayaprakash R, Pinna N, Singh V, Mehta B and Phani A 2008 Mater. Lett. 63242

[7] Li M, Bala H, Lv X, Ma X, Sun F and Tang L 2007 Mater. Lett. 61690

[8] Patzake G, Krumeich F and Nesper R 2002 Angew. Chem. Int. Ed. 4192446

[9] Cao B and Cai W 2008 J. Phys. Chem. C 112680

[10] Kundu S 2014 Colloids Surface A 446199

[11] Nithiyanantham U and Kundu S 2014 Ind. Eng. Chem. Res. 5313667

[12] Shen W, Li Z, Wang H, Liu Y, Guo Q and Zhang Y $2008 \mathrm{~J}$. Hazard Mater. 152172

[13] Ba-Abbad M M, Kadhum A A H, Mohamad A B, Takriff M S and Sopian K 2013 Chemosphere 911604

[14] Baruah S, Jaisai M, Imani R, Nazhad M and Dutta J 2010 Sci. Technol. Adv. Mater. 117

[15] Hong R Y, Li J H, Chen L L, Liu D Q, Li H Z, Zheng Y and Ding J 2009 Powder Technol. 189426

[16] Yadav B C, Srivastava R and Kumar A 2007 Int. J. Nanotechnol. App. 11

[17] Jothi N S, Gunaseelan P and Sagayaraj P 2012 Arch. Appl. Sci. Res. 41698

[18] Chen Z, Wang T, Jin X, Chen Z, Megharaj M and Naidu N 2013 J. Colloid Interf. Sci. 39859

[19] Ovejero G, Rodríguez A, Vallet A, Willerich S and García J 2012 Appl. Catal. B 111586

[20] Chen C C, Liao H J, Cheng C Y, Yen C Y and Chung Y C 2007 Biotechnol. Lett. 29391

[21] Kanmoni V G, Daniel S and Raj G A 2012 Reac. Kinet. Mech. Cat. 106325

[22] Baruwati B, Kumar D K and Manorama S V 2006 Sens. Actuators B 119676

[23] Karin P K 2002 Crit. Rev. Anal. Chem. 32121 
[24] Saxena V, Aswal D, Kaur M, Koiry S, Gupta S, Yakhmi J et al 2007 Appl. Phys. Lett. 901077

[25] Patil D R and Patil L A 2006 Sens. Transducers 70661

[26] Chabukswar V V, Pethkar S and Athawale A A 2001 Sens. Actuators B 77657

[27] Lahdesmaki G, Lewenstam A and Ivaska A 1996 Talanta 43125

[28] Wang X, Miura N and Yamazoe N 2000 Sens. Actuators B 6674

[29] Xu C N, Miura N, Ishida Y, Matuda K and Yamazoe N 2000 Sens. Actuators B $\mathbf{6 5} 163$

[30] Wang Y, Wu X, Su Q, Lee Y and Zhou Z 2001 Solid State Electron. 45347

[31] Moseley P T and Williams D E 1990 Sens. Actuators B 1113

[32] Selvam N C S, Narayanan S, Kennedy L J and Vijaya J J 2013 J. Environ. Sci. 252157

[33] Kumar S S, Venkateswarlu P, Rao V R and Rao G N 2013 Int. Nano Lett. 31

[34] Batool A, Kanwal F, Imran M, Jamil T and Siddiqi S A 2012 Synth. Met. 1612753

[35] Ameen S, Akhtar M S, Nazim M and ShikShin H 2013 Mater. Lett. 96228

[36] Roy P and Shahiwala A 2009 Eur. J. Pharm. Sci. 37363

[37] Vaghasiya H, Kumar A and Sawant K 2013 Eur. J. Pharm. Sci. 49311

[38] Patil D R, Patil L A and Patil P P 2007 Sens. Actuators B 126368

[39] Hankare P P, Sanadi K R, Garadkar K M, Patil D R and Mulla I R 2013 J. Alloys Compd. $\mathbf{5 5 3} 383$

[40] Gawas U B, Verenkar V M S and Patil D R 2011 Sens. Transducers 13445
[41] Patil R P, Nikam P N, Delekar S D, Patil D R and Hankare P P 2014 Sens. Lett. 1201

[42] Kanagadurai R, Durairajan R, Sankar R, Sivanesan G, Elangovan S P and Jayavel R 2009 E.-J. Chem. 6871

[43] Sharma D, Sharma S, Kaith B, Rajput S and Kaur M 2011 Appl. Surf. Sci. 2579661

[44] Chougule M A, Sen S and Patil V B 2012 Synth. Met. 1621598

[45] Barkade S S, Pinjari D V, Singh A K, Gogate P R, Naik J B, Sonawane S H et al 2013 Ind. Eng. Chem. Res. 527704

[46] Chena C C, Fan H J, Jang C Y, Jan J L, Lin H D and Lua C H 2006 J. Photoch. Photobiol.: A 184147

[47] Khezrianjoo S and Revanasiddappa H D 2013 J. Catal. Article ID 582058

[48] Gannu R, Yamsani V V, Yamsani S K, Palem C R, Yamsani M R 2009 AAPS Pharm. Sci. Tech. 10505

[49] Nayak A K, Pal D, Pradhan J and Hasnain M S 2013 Int. J. Biol. Macromol. 54144

[50] Byrappa K, Subramani A K, Ananda S, Rai K M L, Dinesh R and Yoshimura M 2006 Bull. Mater. Sci. 29433

[51] Patil D R 2007 Studies on ZnO based gas sensors Ph.D Thesis

[52] Velmurugan R and Swaminathan M 2011 Sol. Energ. Mat. Sol. C 95942

[53] Senthilkumaar S and Porkodi K 2005 J. Colloid. Interf. Sci. 288184

[54] Chougule M A, Dalvi D S, Mali S, Patil P S, Moholkar A V, Agawane G L et al 2012 Measurement 451989

[55] Dighavkar C 2013 Arch. Appl. Sci. Res. 596

[56] Joshi A, Gangal S A and Gupta S K 2011 Sens. Actuators B 156938 